\title{
A Capoeira no ensino de Português em escola Franco-Caribenha
}

\author{
Luísa Zanini Vargas ${ }^{1}$ \\ Universidade Federal Fluminense, Niterói, RJ, Brasil
}

Resumo: A partir do relato de um projeto sobre a capoeira realizado em uma escola na Martinica, território insular ultramarino francês, o presente artigo visa esmiuçar cada etapa dessa experiência e analisar seus efeitos sobre o corpo discente. O projeto, que durou cerca de dois meses, foi embasado em uma perspectiva comunicativa, acional e intercultural, e contou com o aporte teórico dessas áreas no âmbito do ensino de português enquanto língua estrangeira (PLE). A análise busca englobar o contexto sociocultural da escola e do público e os objetivos linguísticos e sociais propostos pelos docentes, em prol de uma formação à cidadania.

Palavras-chave: Português Língua Estrangeira; Pedagogia Intercultural; Capoeira.

Title: Capoeira in Portuguese Classes at a French Caribbean School

Abstract: Starting from the report of a project about capoeira that took place at a French school in Martinique, this article seeks to describe each step of this experience and analyze its effects on the student body. The project, that was two months long, was based on a communicative, actional, and intercultural perspective, and theoretically supported in those areas in the sphere of Portuguese as a foreign language (PFL). The analysis encompasses the school's and its community's socio-cultural context, as well as the social and linguistic aims proposed by the teachers, in favor of a citizen formation.

Keywords: Portuguese as a Foreign Language; Intercultural Education; Capoeira.

Introdução

O presente artigo busca relatar e refletir criticamente sobre uma experiência de ensino de português língua estrangeira envolvendo a Capoeira em contexto escolar nas Antilhas francesas. O projeto ocorreu no âmbito do Programa de Assistentes de Línguas vivas na França, no ano letivo de 2019-2020, na Martinica. Foi proposto em uma escola da periferia da capital Fort-de-France, o Collège Dillon 2, em uma turma de $4 e$ (quatrième), equivalente ao 8 o ano do Ensino Fundamental no Brasil, composta de cerca de 20 alunos.

Primeiramente, para compreender o contexto, é preciso delimitar, brevemente, os objetivos e funções dos assistentes de língua nesse programa do governo francês. Com mais de um século de existência e cerca de 15 línguas compreendidas, trata-se de um dos mais

\footnotetext{
${ }^{1}$ Licenciada em Letras Português/Francês e suas respectivas literaturas pela Universidade Federal de Pelotas (UFPel) e Mestre em Literaturas Francófonas pela Universidade Federal Fluminense (UFF). Orcid: https://orcid.org/0000-0003-2345-5190. E-mail: luisazaninivargas@gmail.com
} 
antigos programas de mobilidade estudantil. Atualmente recebe candidatos de graduação, especialização, mestrado e doutorado de todos os continentes e não apenas estudantes de Letras ou em formação docente na área das línguas. Contribui na formação profissional sendo frequentemente o primeiro emprego e primeira experiência em docência - e pessoal dos estudantes, já que propicia uma vivência do exterior.

$\mathrm{O}$ assistente de língua trabalha junto ao professor, concomitantemente, em sala de aula. Suas principais missões são desenvolver a oralidade junto aos alunos, participar de (e propor) projetos pedagógicos, animar clubes de língua e contribuir com a elaboração de materiais audiovisuais autênticos para a escola. Tudo isso é realizado em $12 \mathrm{~h} / \mathrm{a}$ semanais distribuídas entre os diferentes professores, turmas e escolas e pelo período de 7 meses: de início de outubro a final de abril. $A$ isso, soma-se a dimensão intercultural, já que, normalmente, os assistentes têm a oportunidade de apresentar sua cultura, sua região e propor atividades e projetos a partir desse tema. Neste último ano letivo éramos 24 assistentes brasileiros na França, sendo 1 na Reunião, 1 em Guadalupe, 2 na Martinica e 8 na Guiana, territórios ultramarinos. Na Martinica fomos cerca de 35 assistentes entre inglês, espanhol e português.

No Collège Dillon 2, sob a orientação da professora franco portuguesa Elisabeth Barbosa, depois das primeiras semanas de primeiro contato e de observação, discutimos a elaboração de um projeto que incluísse algum elemento da cultura brasileira e a partir do qual pudéssemos trabalhar sobre diversos pontos linguísticos do programa escolar. Optamos então pela turma de $4 \mathrm{e}$, que viria a trabalhar com verbos de ações no presente e com vocabulário de atividades e elegemos o tema da Capoeira. O projeto foi organizado em módulos de forma a abarcar as diferentes dimensões e riquezas dessa arte e no intuito sempre de dar voz aos alunos, através de dinâmicas interativas e do uso de ferramentas multimodais (como textos ilustrados, vídeos), evitando assim aulas expositivas, cansativas, ou centradas apenas na língua escrita.

No decorrer das aulas todas as atividades aconteciam com as instruções e explicações em português, adaptado, simplificado, da assistente. A professora eventualmente reexplicava em francês e reforçava a disciplina ora em português, ora em francês ou créole. Nas primeiras semanas os alunos estavam mais resistentes ao português da assistente, mas aos poucos foram se habituando ao sotaque e ao ritmo de fala, diferentes dos das demais professoras de português que tiveram. A primeira é martinicana e aprendeu um português brasileiro-carioca (PLE); a segunda é franco portuguesa (PL2); e a assistente é gaúcha (PLM). A professora que acompanhou o projeto era aberta e esclarecida em matéria de linguística e sempre encorajou o uso das expressões regionais da assistente, de modo a ampliar o repertório dos alunos. Há, no entanto, muitos relatos de assistentes brasileiros que se viam forçados pelos professorestutores a ensinar a variante portuguesa, atitude que mostra, frequentemente, grande desprezo pelas variantes brasileiras. Não foi o caso, e os alunos quando tomavam a palavra já variavam entre o uso do você e do tu, por exemplo, o que demonstra que já compreendem e dominam, dentro do nível de proficiência que possuem, elementos de variantes distintas. 
A aposta, desde o princípio, era, portanto, de pôr em prática atividades fundamentadas em uma pedagogia acional e intercultural, além do seu aspecto naturalmente transdisciplinar. Tomamos como referência de perspectiva acional os modelos cunhados por Christian Puren, didático francês, que trata do ensino de língua com o objetivo de realizar tarefas, de agir dentro da língua, e não apenas decifrá-la ou reproduzi-la. É uma perspectiva centrada no aprendiz e inspirada nas metodologias comunicativas dos anos 70 , vendo a língua para além da simples comunicação, como um meio de ser e de transitar entre diferentes línguas/culturas.

Martine Abdallah Pretceille, em seu livro Vers une Pédagogie Interculturelle (1996, p. 140), pontua que há uma limitação do pensamento quando as disciplinas são todas separadas, categorizadas. Nesse sentido, a interdisciplinaridade é mais acolhedora ao intercultural, pois não reduz, consegue dar conta de diferentes aspectos de um determinado tema. Desta forma, ao explorar diferentes dimensões da capoeira, atentando-se de sobremaneira ao conteúdo e à experiência cultural, a ideia era de evitar cair na armadilha dos textos como pretextos, isto é, de focar o trabalho sobre o texto pura e unicamente nos tópicos linguísticos. Em vez disso, a língua entrava sempre como ferramenta para compreender e apreender algo mais, transitando assim em outras linguagens (musical, performática, corporal, histórica, etc.)

Buscaremos então, através de uma descrição e análise das diferentes etapas desse projeto, do seu efeito e acolhida pelos alunos, refletir sobre uma possibilidade pedagógica que nos dê pistas para a elaboração e aplicação de outras práticas em sala de aula de língua. Para tanto, o relato será feito sem perder de vista a principal função da escola, a de formação de cidadania, com a informação e a atuação em prol do respeito e da tolerância.

É necessário mencionar que grande parte da teoria escrita sobre ensino de Português (brasileiro) para estrangeiros tem como ponto de partida experiências de ensino/aprendizagem em contexto universitário e dentro do Brasil. Isto é, em um contexto em que os estudantes são estrangeiros, adultos e em imersão na língua-alvo. Poucos trabalhos abordam o ensino de PLE em nível escolar no exterior, e quando o fazem, normalmente se trata de alunos nativos do espanhol, sobretudo no espaço do MERCOSUL e de professores que têm o português como L2 ou LE. Entretanto, o que motiva o ensino de português em uma escola na França é diferente do que o motiva numa escola na Argentina, por exemplo. $\mathrm{Na}$ França não há o contato próximo nem a urgência da interação comunicativa, fato que faz com que a LE permaneça estrangeirizada. Percebe-se isso nos trabalhos de José Carlos P. Almeida Filho sobre os contextos e concepções de ensino de PLE: "[a] Língua estrangeira é uma outra língua em outra cultura de um outro país pela qual se desenvolve um interesse autônomo (particular) ou institucionalizado (escolar) em conhecê-la ou em aprender a usá-la." Assim, o interesse em estudar a LE converte-se geralmente em um esforço de estudo e compreensão da linguagem mais amplamente:

A dimensão da linguagem é basilar por servir a todas as outras áreas de estudos do currículo. Ela constrói a experiência de (re) conhecer os fenômenos da natureza, os fenômenos sociais e bastante da experiência com as dimensões, formas, quantificações e cômputos numéricos. Nesse sentido ela é macrocurricular. É através 
da ação das representações que articula que ela permite aos escolarizandos a grande (re) construção do conhecimento nas áreas curriculares (e eventualmente nas disciplinas), no âmbito da cultura geral, portanto, e no âmbito do autoconhecimento (dando conta de quem se é, do que se deve ou não fazer para a felicidade pessoal e o bem-estar coletivo). Trabalhar para desenvolver capacidades da linguagem, seja esse trabalho no contexto que for, significa contribuir fundamentalmente para 0 sucesso da escolarização. (ALMEIDA FILHO, J. C. P., 2005 p. 63)

Nesse âmbito, de aprendizado de uma língua sem necessidades imediatas - ao contrário de uma experiência de imersão - e em contexto escolar, a língua estrangeira cumpre muitas vezes uma função de apoio à língua materna. Observa-se no Brasil, como na França e em muitos países, um déficit na educação no que diz respeito ao desenvolvimento das capacidades de leitura e interpretação em língua materna, seja qual for o nível escolar ou a situação econômica de seu público, fato que reflete em todas as outras disciplinas escolares. A língua estrangeira serve para, nesses casos, além de dar bases para a compreensão e comunicação na língua-alvo, dar elementos de comparação que ajudem a refletir e apreender a própria língua materna, de sobremaneira em variantes de prestígio.

\section{Contexto cultural e escolar da Martinica}

Antes de avançar nas etapas do projeto, convém pincelar alguns pontos sobre a sociedade e o contexto escolar na Martinica, para compreender o quadro dentro do qual foi desenvolvido. Tal como no Brasil, as Antilhas francesas possuem uma história de colonização violenta, baseada na exploração de terras para cultivo e exportação (sobretudo de açúcar e banana) e de mão de obra humana, através da economia escravocrata. Por conseguinte, a sociedade é majoritariamente negra e mestiça, e apesar disso ainda hoje são os brancos os detentores de grande parte das riquezas da ilha, herdeiros dos grandes senhores de terra da época colonial. As cicatrizes e marcas dessa época seguem visíveis, mas também se intensificam a revolta, o descontentamento. Uma prova simbólica disso é o fato de manifestantes martinicanos terem depredado a estátua de Josefina Bonaparte (martinicana, branca, que foi a esposa de Napoleão): o monumento, na principal praça da capital Fort-deFrance foi decapitado e tingido de manchas vermelhas. E mais recentemente, dentro de um movimento internacional que tem problematizado essas homenagens a personagens históricos de importância duvidosa, foi derrubado e queimado.

Além disso, os franceses de territórios ultramarinos, apesar de disfrutarem juridicamente dos mesmos direitos que os franceses do hexágono - forma de apelação da França continental na Europa de modo a evitar o termo metrópole, que remete à época colonial -, eles não recebem o mesmo tratamento socialmente. O racismo e a xenofobia estão arraigados na sociedade francesa e antilhanos e descendentes de antilhanos nascidos no hexágono ainda são tratados, com frequência, como estrangeiros. A questão racial ainda adquire outras camadas, na medida em que antilhanos ainda recebem um tratamento menos ruim por serem mestiços, não tão negros quanto os negros africanos ou descendentes de africanos. 
Infelizmente acontece uma reprodução dessa violência dentro dos próprios territórios. Por ainda pertencerem à França, diferentemente de seus vizinhos independentes (Santa Lúcia, Dominica, Barbados, Haiti, etc.), de onde recebem muitos emigrantes, esses territórios franceses possuem maior estabilidade econômica e benefícios sociais, inclusive para estrangeiros. Disso decorre o status inferiorizado desses estrangeiros, e a xenofobia acontece em muitos níveis e está presente inclusive na escola. Luísa Zanini Vargas (2018, p. 89), no capítulo de sua dissertação sobre a pedagogia intercultural e seus desafios, em diálogo com o trabalho de Abdallah-Pretceille, fala que:

Para vencer o preconceito, é preciso entender que ele não está apenas no nível do discurso, do conteúdo, mas que ele desempenha uma função até política e ideológica (de poder, de controle), e é essa a raiz, combatendo-a podem ser neutralizados, aos poucos, seus efeitos destrutivos [...]. A luta contra o racismo deve sair da teoria e englobar a luta contra os estereótipos e o etnocentrismo.

Ainda hoje existe essa ideia de superioridade advinda de grandes potências econômicas e culturais como a França. A manutenção dos discursos de ódio e da estereotipia agem a serviço do etnocentrismo, do controle de uma nação sobre determinados territórios. As demais Antilhas, independentes, são pequenos territórios com a economia baseada no setor turístico e dependem de grandes potências como Estados Unidos, Inglaterra, França, para se manterem. Ademais, são muito pobres, à vista disso há um grande fluxo migratório para as ilhas francesas, mais estáveis socioeconomicamente. Todavia, ao chegar na Martinica, em Guadalupe, em busca de oportunidades, esses estrangeiros encontram trabalhos extremamente precarizados, vão viver em periferias onde há os maiores índices criminais, se veem muitas vezes encurralados em condições de vida piores ainda que em suas ilhas natais.

Como mencionado na introdução, a instituição onde o projeto foi aplicado é uma escola periférica, em um bairro mais popular da capital, no qual vivem muitas famílias originárias dessas outras ilhas. Nas 3 turmas em que trabalhamos nessa escola, cerca de $10 \%$ dos alunos eram estrangeiros (vindos sobretudo do Haiti e de Santa Lúcia). A escola tinha turmas de francês para estrangeiros (FLE) quinzenalmente e profissionais cuja função era a de ajudar esses alunos em sua adaptação. Contudo, os horários de aulas sempre batiam com os de língua portuguesa (ou espanhola para as turmas de espanhol), e esses alunos, em especial, só estavam presentes quinzenalmente. O fato mais duro que pudemos observar é que os colegas de aula e alguns funcionários da escola maltratavam esses alunos verbalmente, simbolicamente e até fisicamente, em atitudes de bullying e de profundo desprezo.

Para demonstrar a dificuldade e como ela é reconhecida em nível institucional e governamental, trazemos alguns dados: há no total 54 estabelecimentos escolares denominados collège da ilha, que atendem ao nível equivalente ao segundo ciclo do Ensino Fundamental no Brasil. Esse collège em específico é um dos 9 que fazem parte de um REP+, réseau d'éducation prioritaire renforcée, rede de educação prioritária reforçada. Esse sistema visa reduzir as desigualdades, através de dispositivos educativos, em prol de melhores resultados escolares. Nesse sentido, a presença do assistente de língua e as aulas de FLE são exemplos de dispositivos de inclusão. 
Enfim, todo o contexto socioeconômico do corpo discente dessa instituição escolar contribui para a emergência de tais demonstrações agressivas de intolerância e desrespeito ao outro. É nesses termos e em uma turma particularmente desafiadora em matéria de disciplina e respeito às regras de sala de aula que resolvemos experimentar esse tema. Buscou-se abordá-lo a partir da reflexão das atitudes dos próprios alunos em sala de aula e em relação aos colegas de diferentes origens em última instância. A professora responsável, nesse sentido, exerceu seu papel de educadora, ao conversar com a turma sobre essas demonstrações de preconceitos quando aconteciam em sua presença. Se necessário, interrompia a aula para conversar a respeito. Além disso, com o projeto esperávamos incentivar a autoconfiança dos alunos em suas próprias origens e história, que crescesse em respeito e tolerância com relação aos demais.

É um dever da educação abrir portas para seus cidadãos, seja através das artes, dos idiomas, dos conhecimentos técnicos e científicos, das humanas ou das exatas. $\mathrm{O}$ essencial é não perder de vista a conexão de tudo, os diálogos que transcendem as ditas fronteiras. A aceitação de si e a observação do outro são apenas uma parte da constituição de um indivíduo e, por extensão, de uma cultura. (VARGAS, 2018, p. 91)

Bernardine Cadrot-Brival, em um artigo sobre as práticas educativas tradicionais e a formação socio-cultural em contexto escolar na Martinica, faz uma reflexão sobre o racismo arraigado na sociedade e, em decorrência disso, na escola. Ela detalha as práticas escolares pós abolição, em que ex-escravos tinham acesso a uma vida melhor através da educação, contudo repetiam a mesma violência sofrida, ao modelo dos senhores de escravos, em casa, com suas crianças e na escola. Isso tornava a vida das crianças um constante suplício, pois em momento nenhum eram incentivadas ou tinham espaço para se expressar e se descobrir enquanto seres sociais. A autora ainda fala que muitas dessas práticas escolares ainda funcionam desta forma, não mais com os castigos corporais da época, mas frequentemente com muita rigidez vide violência verbal e pouco espaço de expressão da própria identidade, o que acarreta um mal-estar psíquico nos alunos. Pois além de tudo, a educação sempre prezou a cultura europeia e os alunos que eram tratados com mais dignidade eram frequentemente os alunos que vinham de famílias com situações econômicas mais confortáveis, frequentemente de pele mais clara. Tudo isso está em processo de mudança. Observa-se cada vez mais a inclusão do créole no ensino, e um trabalho sobre a própria cultura e identidade dos habitantes da ilha. No entanto, a rigidez e essas formas de preconceito ainda estão muito enraizadas e, como mencionado antes, o preconceito social ainda se manifesta em diversos níveis.

Ademais, na Martinica existe uma luta muito similar à capoeira em diversos aspectos, chamada Ladja ou Danmyé. Além de se aparentar à capoeira pela origem histórica, também conserva alguns ritos em comum como o acompanhamento musical, marcado por tambores e pelo rondó - cantos puxados por um mestre e respondidos pelo coro; a disposição das pessoas em roda e dois lutadores de cada vez. Se diferencia um pouco pela língua, o créole, e pelos movimentos geralmente muito rápidos (que se aproximariam mais ao estilo Regional ou Brasil de capoeira, em oposição à capoeira Angola), e com muito mais contato físico, enquanto 
na capoeira há mais esquiva, menos toque. Também se trata de uma arte marcial muito conhecida mundialmente, a Capoeira, e que desperta a curiosidade dos alunos. Assim, saber que na Martinica há algo da mesma família, relacionar as duas artes, provocou uma surpresa agradável na turma, no sentido de afirmação e valorização da própria identidade cultural. Desta forma, o ensino de língua portuguesa entra na educação desses adolescentes com essa função muito mais ampla, de abrir portas e de autoconhecimento, mencionada anteriormente. A língua estrangeira é um instrumento que serve para reconhecer esse espelho que é o outro, no sentido das semelhanças e da valorização dessas semelhanças do outro, que pode ser incorporada levando à valorização de si.

\section{Metodologia}

Como mencionado acima, as primeiras semanas de aula com a assistente foram de apresentação, observação, adaptação. Num dos primeiros encontros com cada turma a professora abriu o espaço aos alunos para fazerem perguntas em português à assistente, aproveitando para revisar e introduzir novos pronomes interrogativos e revisar vocabulários diversos, de acordo com as questões que fossem surgindo (atividades, profissão, família, esportes, hobbies, animais domésticos, geografia, etc.). "Tu praticas algum desporto?", na variante portuguesa, ou "Você pratica esportes?" foi unanimidade em todas as turmas. A resposta da assistente, danças e capoeira, fez com que os alunos demonstrassem particular interesse e curiosidade com relação à segunda atividade. Uns queriam demonstrar que já tinham praticado também e sabiam gingar, outros tinham um primo ou um vizinho que praticava, outros gritavam em francês a definição "é uma arte marcial com instrumentos, com música". O fato de ser um elemento da cultura brasileira com que tinham alguma familiaridade e de que tinham algum conhecimento os enchia de orgulho e empolgação.

Foi nesse contexto que, em conversas posteriores, a professora e a assistente elegeram o tema para o projeto. Em seu artigo Aprender conteúdos para aprender língua estrangeira: uma experiência de ensino alternativo de $P E$, Ana Cecilia Cossi Bizon propõe que os próprios alunos decidam os temas a serem trabalhados, de acordo com seus objetivos em aprender a língua. A autora acredita que a língua estrangeira é mais facilmente aprendida quando se leva em conta os interesses do público-alvo e materiais e situações que tragam a língua em uso e para o seu uso efetivo, ao invés de um conteudismo que vê a progressão a partir do que é considerado mais fácil ou mais difícil de aprender. Propõe a partir dessa escolha que cada unidade seja construída levando em consideração sete elementos. 0 primeiro, Tema e tópicos, é a definição do conteúdo a partir do qual todo o resto será trabalhado; o segundo, Funções comunicativas, são os atos de fala/escrita em linhas gerais; o terceiro, Recortes comunicativos, os contextos mais específicos de comunicação; em seguida os Expoentes de formulação; o Léxico a ser desenvolvido; a Forma, portanto questões mais ligadas à gramática, sintaxe; e por fim o Material Extra, tudo o que possa ajudar a reforçar o conteúdo aprendido, preferivelmente materiais autênticos, na linha da abordagem comunicativa. 
Desta forma, foram definidos o tema geral e os recortes para cada módulo, dentro de cada qual havia um ou mais objetivos comunicativos. Em seguida, foram definidos os materiais, instruções e ferramentas que seriam dados aos alunos para a realização das atividades, visando à utilização efetiva da língua, seja em compreensão oral e escrita, ou em produção oral (principalmente) e escrita.

\section{Módulo 1 - A canção}

Decidimos dar início às atividades através de uma canção de capoeira, muito utilizada em grupos infantis no Brasil. A escolha foi feita pelo objetivo principal, por ser uma aula de língua, ser a expressão da fala, da oralidade. Fizemos uma breve introdução e sensibilização perguntando à turma o que conheciam sobre a capoeira. De imediato muitos tiveram alguma reação oral/gestual para defini-la. Em seguida dividimos a turma em grupos de 4 alunos, e para cada grupo foram dados alguns papéis soltos com verbos em português. Fizemos uma primeira escuta da música como sensibilização e explicamos a atividade: os grupos deveriam tentar colocar os verbos em ordem, de acordo com o momento em que aparecessem na escuta da canção. O primeiro grupo que conseguisse achar a ordem corretamente ganhava adesivos (era o método da professora para premiar os alunos nas atividades). No final da aula receberam a letra da música com lacunas no lugar dos verbos para completarem como dever de casa. Segue a letra completa abaixo:
A EIOU - U OIE A - A EIOU
Vem criança vem jogar
Eu aprendi a ler
Aprendi a cantar
E foi na capoeira
O meu pai e minha tia
Sou criança sou pequeno
Mas um dia eu vou crescer
Vou treinando capoeira
Pra poder me defender
Que eu aprendi a jogar
Capoeira é harmonia
Eu estudo na escola
E amor no coração
E treino na academia
Capoeira tem criança
Eu respeito a minha mãe
O futuro da nação

$\mathrm{Na}$ aula seguinte retomamos a canção para trabalhar com a compreensão da letra. $\mathrm{A}$ partir dos verbos, que eram em sua grande maioria relativamente transparentes para os alunos, semelhantes em francês, não foi muito difícil achar o significado das frases, de construção sintática simples. A letra da canção foi projetada no quadro e todos juntos foram desvendando o significado. O papel da professora e da assistente era o de fornecer algumas ferramentas que ajudassem na associação e decodificação de palavras e construções frasais, nunca o de traduzir. E depois da compreensão o exercício da escuta foi feito novamente. Desta 
vez, porém, os alunos cantaram junto, pudemos observar desde o início da aula que eles tinham ficado com a música na cabeça e haviam provavelmente ensaiado em casa.

Na terceira e última aula do módulo fizemos uma atividade de canto coral. Foram feitos exercícios de aquecimento vocal, com as instruções dadas em português e algumas dinâmicas de divisão da turma para cantar as diferentes partes. Por exemplo, em uma divisão meio a meio, metade da turma fazia o papel do Mestre, daquele que puxa o canto e canta as estrofes, a outra metade fazia o canto responsório, do coro, o refrão depois de cada estrofe. E depois mudávamos os grupos. Antes da atividade foi explicado aos alunos como acontecia o canto em uma roda de capoeira, a partir da constatação dos próprios alunos, através da escuta da canção, de que havia um adulto que cantava e um coro de crianças que respondia o refrão.

\section{Módulo 2 - Os instrumentos}

Para o segundo módulo foram previstos áudios e imagens para fazer um trabalho de escuta e associação do som ao instrumento. Havia a intenção de levar os instrumentos à escola, o que não ocorreu devido a dificuldades administrativas. Primeiramente mostramos um vídeo em que apareciam os instrumentos, o som que produziam na capoeira, separadamente, e seus nomes. Em seguida passamos para a atividade de associação. Os alunos escutavam o áudio e o primeiro que levantasse a mão e dissesse o nome do instrumento corretamente ganhava um adesivo. Receberam uma ficha com as imagens dos instrumentos na aula seguinte e de memória tinham que completar com os nomes.

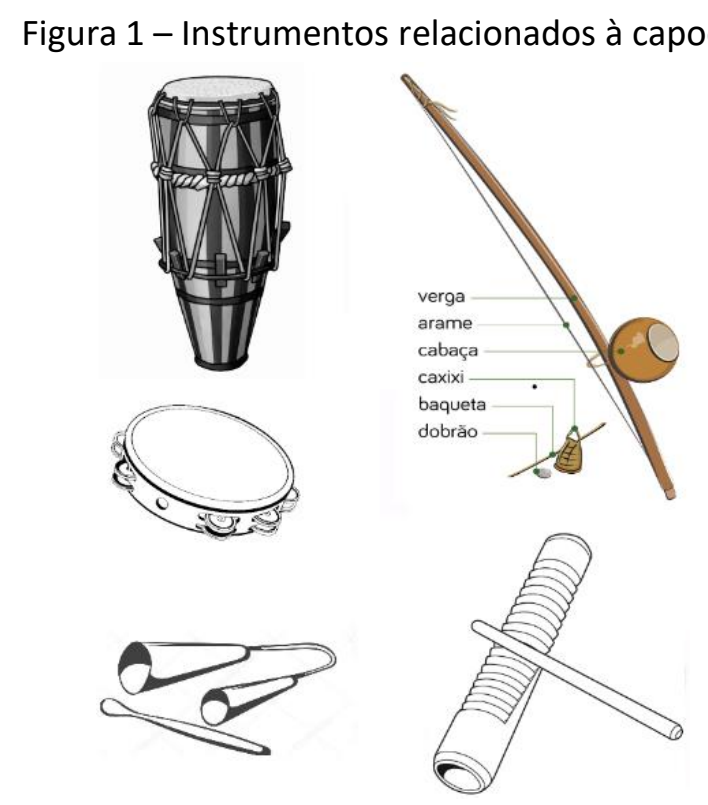

$\mathrm{Na}$ segunda etapa do módulo trabalhamos com uma sensibilização de ritmo. Escutamos novamente o som que os diferentes berimbaus faziam e perceberam que o segundo fazia a melodia inversa do primeiro. Estabelecemos juntos um código para cada instrumento de acordo com os sons altos (agudos) e baixos (graves) que cada um fazia e em 
que ordem e tempo, escutávamos o instrumento e os alunos diziam o código para escrevermos no quadro (Tum - Tá - Tum/ Tá - Tum - Tá). Por último dividimos a turma em grupos e cada grupo representava um instrumento. Alguns eram o Atabaque e faziam percussão corporal (batidas no peito e nas pernas) para mimetizar esse instrumento, outros eram o pandeiro e usavam as palmas das mãos, outros eram os caxixis e faziam os chiados com a boca, outros eram os berimbaus e faziam o som com a voz e os códigos criados). No fim juntamos todos os instrumentos-humanos e o resultado não foi excelente, mas pelo menos rendeu muitas risadas e gerou consciência do ritmo nessa arte. Aproveitamos a atividade para relembrar o vocabulário do corpo humano.

\section{Módulo 3 - Os Movimentos}

Esse foi o módulo preferido dos alunos, e o que durou mais aulas na sua realização. $\mathrm{Na}$ primeira aula ensinei 3 primeiros movimentos, a ginga - a dança base, um movimento de ataque, a bênção, e um movimento de defesa, a esquiva de frente. Antes de mostrar esses movimentos fizemos um aquecimento, trabalhando oralmente com as partes do corpo e com instruções e expressões de direção (coloca a mão direita na cabeça, alonga o pescoço/ com as pernas esticadas, coloca as duas mãos nos pés/ coloca a mão direita no cotovelo esquerdo, alonga o braço esquerdo). Em seguida começamos a fazer os movimentos, começando pela ginga. Da mesma forma, com instruções de direção (um passo pra direita; perna esquerda pra trás; pra frente e um passo pra esquerda; perna direita pra trás; pra frente e um passo pra direita...).

$\mathrm{Na}$ aula seguinte solicitamos a alguns voluntários que demonstrassem os movimentos trabalhados na última aula e aos colegas que dissessem os nomes. Depois da recapitulação passamos um vídeo de duas adolescentes demonstrando outros movimentos básicos de capoeira, com os nomes dos movimentos. A cada movimento novo pausávamos, algum voluntário o realizava e a turma repetia o nome. Ao final do vídeo fizemos um teste rápido: a assistente realizava os movimentos e a turma dizia o nome e no final listamos os movimentos no quadro, classificando junto com a turma em movimentos de deslocamento (ginga), ataque (Meia lua de frente, meia lua de compasso e bênção), defesa (esquivas de frente, de lado e de costas e cocorinha) e floreio (aú).

A terceira e a quarta aula foram realizadas fora da sala, no pátio da escola. Neste momento, colocamos de fundo a música com que havíamos trabalhado nas primeiras aulas, nos dispusemos em roda, sentados, e fizemos dinâmicas de duplas. A assistente pedia a um voluntário para fazer a demonstração da junção de um movimento de ataque com um de defesa. Em seguida, todos os alunos que quisessem participar também o faziam, dois a dois, enquanto os demais acompanhavam cantando e com palmas ritmadas. Na quarta repetimos a atividade com outros movimentos e com os próprios alunos fazendo o acompanhamento musical (sem o apoio do áudio).

Houve um dia, durante a greve geral, em que apenas a metade da turma compareceu. Então, para que a metade não ficasse sem a continuidade do projeto, trabalhamos com as 
direções, através de um jogo. Os alunos se dividiram em dois grupos: um orientado pela professora e outro pela assistente. Um integrante do grupo era vendado e os demais escondiam um objeto na sala. O exercício era de produção e compreensão oral com instruções de direção, ferramentas que fornecemos no início da aula, ao explicar o jogo. O aluno vendado seguia as instruções dos demais, que, um de cada vez, ditavam os passos (dá 1 passo pra esquerda, dá 5 passos pra frente, vira pra direita, anda 10 passos pra frente). No início da atividade eles perguntavam e olhavam o quadro constantemente para ajudar na construção das frases, mas 3 ou 4 rodadas mais tarde já estavam todos craques no jogo e nas instruções de direção em português. Além disso, no final desses 3 primeiros módulos, realizamos um teste sobre os instrumentos e os movimentos da capoeira, em uma aula posterior, e um jogo de mímica com os verbos trabalhados durante o projeto.

Esse conforto em realizar as tarefas em um módulo em que se trabalhou com instruções orais, compreensão oral e realização de movimentos corporais como resposta e demonstração de compreensão pode ser explicado em parte pela teoria da resposta física total, de James Asher. O autor propõe aplicar um método natural na aquisição de língua materna em aprendizado de língua estrangeira, pois as crianças antes mesmo de falarem são capazes de entender instruções e agir de acordo. Esse método, segundo Asher, colocaria menos pressão na aprendizagem, tornando-a mais fluida, pois os alunos se acostumariam a serem primeiramente ouvintes e intérpretes e em seguida se expressariam na medida em que se sentissem confortáveis, respeitando o ritmo de cada um, o que evitaria o desenvolvimento de bloqueios. Além disso, o aprendizado ficaria mais interiorizado pois enfatiza o significado mais que a forma, além da necessidade de se entender um comando para poder agir.

\section{Módulo 4 - A história}

No último módulo, que teve a duração de duas aulas, trabalhamos com um texto curto sobre a história da capoeira, fizemos uma leitura projetada no quadro, para dar as ferramentas de decodificação aos alunos. Frase por frase, vinha um aluno sublinhar as palavras e expressões-chave, que fossem mais transparentes e resumissem a ideia da sentença. Na aula seguinte, em duplas, responderam a um quiz, a partir do texto, com questões de Verdadeiro ou Falso e Múltipla Escolha (todas na ordem de aparição da resposta no texto). Também receberam uma linha do tempo com imagens de personagens e eventos fora de ordem para colar no devido lugar. Tivemos muitas conversas no decorrer do projeto sobre a história, o contexto e a motivação pro surgimento da capoeira no Brasil, mas nas últimas aulas pudemos trabalhar com essas informações mais organizada e detalhadamente e conversamos sobre as heranças da escravidão, o racismo, comparamos um pouco mais a história da Martinica e a do Brasil.

Infelizmente não pudemos dar seguimento ao projeto já que o movimento grevista começou a se intensificar bem na época em que começaríamos o último módulo, o de criação de cartazes e preparação de uma apresentação para o resto da escola sobre a capoeira. Pensávamos, com essa última etapa, que seria feita em grande parte em sala de aula sob a 
supervisão da professora e da assistente, em fechar o ciclo com criatividade e com o intuito de fazer os alunos retransmitirem esses aprendizados para mais colegas e para outros professores e funcionários da escola. Afinal ler, escutar, repetir novos conhecimentos são importantes no aprendizado, mas quando somos capazes de ensiná-lo, passá-lo adiante é que ele se sedimenta. Além dessa tarefa final, outro registro que teria ajudado a avaliar os resultados seria o das reflexões dos próprios alunos e em língua materna, por ainda não dominarem a língua portuguesa o suficiente, oralmente ou por escrito. Seria uma ideia para projetos futuros.

O que foi possível fazer foi gravar o testemunho de 4 dos cerca de 20 alunos da turma, alguns meses depois do projeto. Quando indagados sobre a participação e integração da turma todos os quatro responderam positivamente: a primeira aluna falou que "houve muita entreajuda", o segundo falou que "em relação a alguns alunos que não estavam realmente integrados sim, eu vi, eles participaram e se aproximaram das outras pessoas da turma", o terceiro disse que "sim, eles tentavam" e a quarta "sim, eles participaram mais". No que se refere ao comportamento e ao respeito mútuo e em relação ao professor a primeira aluna afirmou que "sim, um pouco, melhorou um pouco", o segundo e o terceiro afirmaram que sim e a quarta não notou muita diferença. Sobre o que aprenderam ao longo do projeto, todos citaram os movimentos, alguns citaram os instrumentos e uma a música, e o segundo aluno ainda acrescentou "aprendi a me comunicar melhor com os meus colegas". Todos falaram que gostariam de ter mais projetos desse estilo, principalmente envolvendo cultura, música, dança e o segundo aluno disse que "é melhor ter projetos assim do que fazer só português, só português, isso ajuda, é melhor". Todas as respostas foram faladas em francês, estão aqui traduzidas a partir da transcrição. Mesmo que não se tenha recolhido os relatos da integralidade dos alunos, essa amostra já ilustra a receptividade e impressão positiva que o projeto deixou. Os alunos empregaram muitos termos positivos e afetivos e para falar da sua apreciação do projeto: a primeira aluna falou duas vezes que gostou muito do projeto, o segundo disse "gostei muito, apreciei tudo, não tem uma coisa em particular que eu gostei mais porque foi um trabalho que envolveu todo mundo", a quarta aluna ao citar o que ela tinha gostado no projeto acaba falando de cada módulo, um por um e no final conclui "é, eu gostei de tudo!".

\section{Considerações finais}

Apesar de não ter sido concluído como imaginado na base, o projeto rendeu muitas reações, conversas, dúvidas e comentários interessantes. Claramente os alunos gostaram do tema, que despertou sua curiosidade e motivação para a participação em todas as atividades, algumas mais que outras. Observamos um maior interesse no módulo dos movimentos, o aprendizado acontecendo mais corporalmente, com a performance física e em conjunto com os colegas. Um dos alunos, quando foi fazer a movimentação de ataque com uma colega que deveria fazer a de defesa, se precipitou e quase a feriu. Paramos a atividade para conversar sobre isso, dizer que atingir o outro não era o objetivo da capoeira, e que antes de se 
movimentar, o que já é uma linguagem, uma expressão, é preciso saber escutar o ritmo e observar o outro, como numa conversa; pois além de luta a capoeira também é dança e segue uma cadência. A partir disso todos ficaram mais atentos e não houve mais acidentes em potencial.

No início das aulas com a assistente os alunos costumavam dar bom dia ora em português ora em francês, ao chegar em aula. No decorrer das aulas notamos um considerável esforço em evitar o francês em determinadas situações de aula, quando se tratava de expressões que já dominavam, e uma maior coragem para tentar se expressar nas atividades propostas, fato que associamos à motivação que nasceu do projeto. $\mathrm{O}$ envolvimento com o assunto, que os fez vibrar corporalmente, musicalmente, ludicamente além de fazer pensar na própria história e identidade a partir da história brasileira está certamente na origem dessa motivação. Para Almeida Filho (1992, p. 21),

[...] a linguagem não pode ser tomada como objeto exterior ao aprendiz, mas sim como processo construtivo e emergente de significações e identidade. Aprender uma língua não é somente aprender outro sistema, nem passar informações a um interlocutor, mas construir no discurso (a partir de contextos sociais concretos e experiências prévias) ações culturais apropriadas.

Nesse sentido, a capoeira, esse patrimônio cultural em todas as suas dimensões funcionou como um espelho para esses alunos se entenderem e se enxergarem melhor. Abdallah-Pretceille fala dos conceitos de cultura e identidade cultural como mitos, como conceitos-ferramenta suscetíveis de serem apropriados através de determinados parâmetros político-ideológicos.

Portanto, não seria de maior interesse definir culturas de maneira clara, precisa; seria necessário ter uma atitude mais interrogativa que descritiva, nesse sentido. Nisso entra a questão da alteridade, do outro como espelho, e que para haver um sentimento do eu, antes até da noção do eu, é preciso haver a presença do outro, um jogo de imitação e diferenciação. (ABDALLAH-PRETCEILLE, 1996, p. 37 apud VARGAS, 2018, p. 86)

Dentro das ideias de educação, em sua grande maioria compartilhadas entre a professora e a assistente, sempre esteve presente essa noção de valorização de si, da própria cultura e de respeito ao outro, através de trabalhos sobre culturas de outros povos e lugares. A desconstrução de ideias preconceituosas aconteceu em vários níveis, como falado ao longo desse trabalho. "A pedagogia intercultural é meio, assim, não de fomento à pluralidade de culturas em si, mas de abertura do leque das possibilidades de discursos sobre as culturas." (VARGAS, 2018, p. 90). É a partir da desconstrução de certas ideias recebidas da sociedade em que se vive que se torna possível construir novos discursos sobre as pessoas e as culturas, discursos mais abertos e sensíveis a realidades diversas, de modo a criar mais pontes, conexões, menos barreiras.

Com a observação do comportamento da turma durante as atividades e até fora de sala de aula antes, durante e depois do projeto e em comparação com as outras turmas e níveis, pudemos constatar o impacto positivo do projeto. A princípio tratava-se de uma turma 
como as outras do mesmo estabelecimento escolar: com alunos provenientes de diferentes esferas sociais, desrespeitosos com os colegas e professores, indisciplinados, desinteressados em grande parte pelo aprendizado de língua portuguesa. Soma-se a isso a idade, o início da adolescência e o temperamento rebelde da grande maioria. No início do projeto ainda havia um pouco de resistência à língua, à professora, à assistente, às propostas. Aos poucos foram aderindo ao projeto com mais voluntarismo. Depois houve o início da pandemia, do confinamento, e diferentemente dos Lycées (instituições escolares de nível equivalente ao Ensino Médio no Brasil), nos quais houve um efetivo ensino à distância, os alunos do Collège Dillon 2 sofreram com a precariedade de meios de acessar à educação continuada.

No entanto, o contrato de assistente renovado por mais um ano letivo, foi possível retomar o contato e o trabalho com as diferentes turmas a partir de início de outubro. A turma com a qual desenvolvemos o projeto, desde o início desse novo ano (atualmente em nível $3 e$ - troisième - equivalente ao nono ano no Brasil), é a que se mostra mais aberta à execução das atividades propostas em língua portuguesa, com uma adesão e participação quase total da turma na maior parte das vezes. Voltaram a ter aulas com a primeira professora, martinicana, que também está aberta para propor projetos junto com a assistente, e sempre cumprimentam ambas em português quando chegam em aula e quando as veem nos corredores e no pátio da escola. Com relação ao bullying, fica claro que as exclusões que existiam no ano anterior cessaram. Os alunos estão mais integrados entre eles e demonstram maior maturidade. Mais inclusive do que aqueles que estavam em $3 e$ no último ano e que agora estão no Lycée, em sua maioria ainda com a assistente, pois foram para os Lycées onde trabalha. Grande parte da turma se voluntaria a tomar a palavra quando solicitado, sentemse encorajados a assumir essa postura, não têm mais tanto medo ou vergonha de "errar" ou de não ter bem compreendido a tarefa. Menos rigidez é necessária da parte da professora para aplicar a disciplina, e com isso se perde bem menos tempo que nas outras turmas, ainda muito dispersas e difíceis de organizar. O respeito mútuo melhorou claramente nessa turma, e isso também é um incentivo para os docentes proporem mais projetos desse tipo nas demais turmas.

\section{Referências}

ASHER, J. The total physical response approach to second language learning. Modern Language Journal, 53:3-17, San Jose, 1969. https://doi.org/10.1111/i.15404781.1969.tb04552.x

ABDALLAH-PRETCEILLE, M. Vers une pédagogie interculturelle. Anthropos: Paris, 1996.

ALMEIDA FILHO, J. C. P. O ensino de Português como língua não-materna: concepções e contextos de ensino. Universidade de Brasília, 2017. Disponível em: https://museudalinguaportuguesa.org.br/wp-content/uploads/2017/09/ENSINO-COMOLINGUA-NAO-MATERNA.pdf. Acesso em: 10 set. 2020.

ALMEIDA FILHO, J. C. P.; LOMBELLO, L. C. Identidades e caminhos no ensino de português para estrangeiros. Campinas: Pontes Editora, 1992. 
CADROT-BRIVAL, B. Pratiques éducatives traditionnelles en contexte martiniquais et création d'une identité culturelle. Dossier Archipelies: Transmettre et Être : Fabriquer le sujet, pérenniser la société. Septembre, 2020. Disponível em : https://www.archipelies.org/746\#tocto2n6. Acesso em: 10 set. 2020.

COSSI BIZON, A. C. Aprender conteúdos para aprender língua estrangeira: uma experiência de ensino alternativo de PE. In: ALMEIDA FILHO, J. C. P.; LOMBELLO, L. C. Identidades e caminhos no ensino de português para estrangeiros. Campinas: Pontes Editora, 1992.

PUREN, C. De l'approche communicative à la perspective actionnelle. Le Français dans le Monde, $\mathrm{n}^{\circ} 347$, sept.-oct. 2006, pp. 37-40. Paris: FIPF-CLE international.

VARGAS, L. Z. Oralidade e cultura em Kirikou et la Sorcière e Ti Jean l'Horizon. 2018. 98 f. (Dissertação de Mestrado em Literaturas Francófonas) - Universidade Federal Fluminense. Niterói, 2018.

Recebido em: 19/09/2020. Aceito em: 16/11/2020. 